\title{
FROM GADGETS TO THE SMART GRID
}

Batteries are key to powering portable devices and developing a modern energy network. Researchers are scrambling to develop iterations that can overcome the current limitations. By Sujata Gupta, infographic by Nigel Hawtin.

\section{HOW A BATTERY WORKS Batteries store electricity in the form of chemical energy}

Batteries contain a positive cathode and a negative anode. These electode terminals are made up of different materials depending on the battery type.

When a device is connected to the battery, a chemical reaction occurs that generates positively charged ions and negatively charged electrons. The ions flow through electrolyte to the cathode; whereas the electrons (that cannot penetrate the electrolyte) travel around the outer circuit powering a device en route to the cathode.

Disposable batteries die when the anode or cathode runs out of the chemical needed to catalyse the reaction.

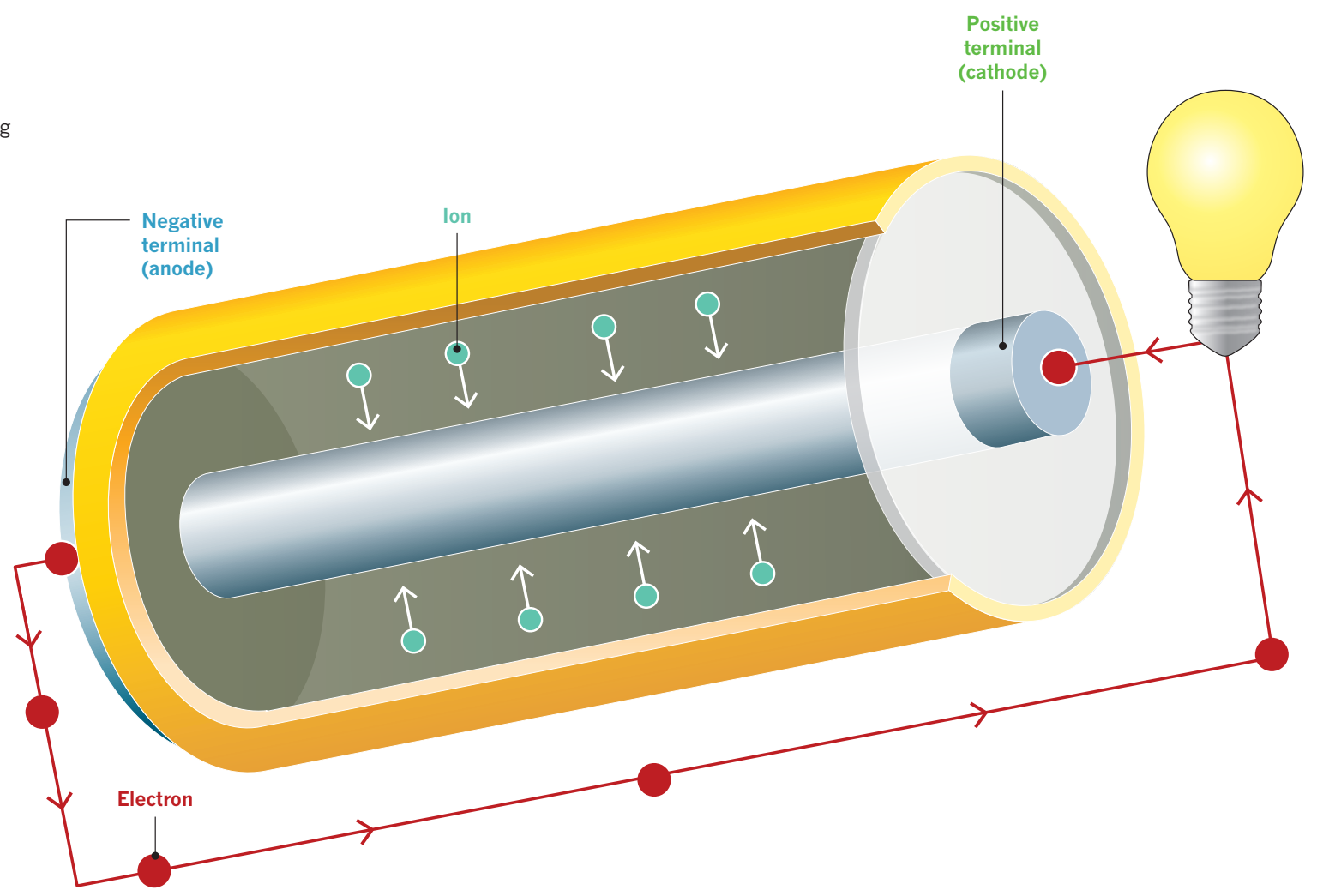

\section{RECHARGEABLE BATTERIES}

When a device is recharged, electric energy from the charger (such as a phone charger plugged into a wall) is applied to the chemical system to reverse the process and restore the battery's charge. Rechargeable batteries are thought to degrade because of the irregular movement of ions in the electrolyte.

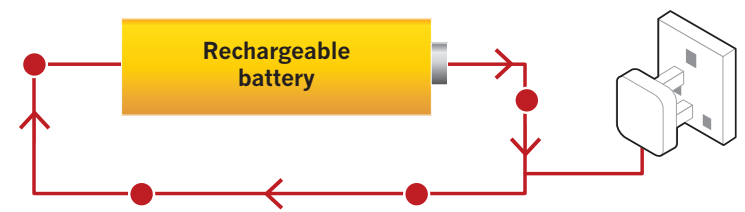

TYPES OF RECHARGEABLE BATtERIES

The lifetime, cost, energy storage and re-usability of the battery are determined by the material used. This also dictates whether the battery is best used for devices that do not consume much energy or in those that do.

\section{Capacity}

Ability to supply

electric energy

Performance

How well high-drain

devices are powered

Recharge cycles

The number of times

the battery can be

recharged in its lifetime

Toxicity

Composition and ease

of recycling

Affordability

Cost to consumer

\section{Alkaline}

Best for low-drain and infrequently used

devices such as flashlights

Capacity

Performance

Recharge cycles

Toxicity

Affordability
Nickel cadmium

Best for high-drain devices such as biomedical

equipment, professional video cameras and power tools

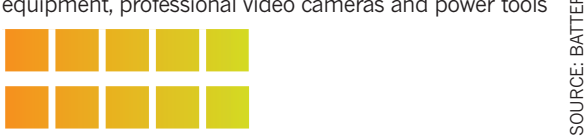




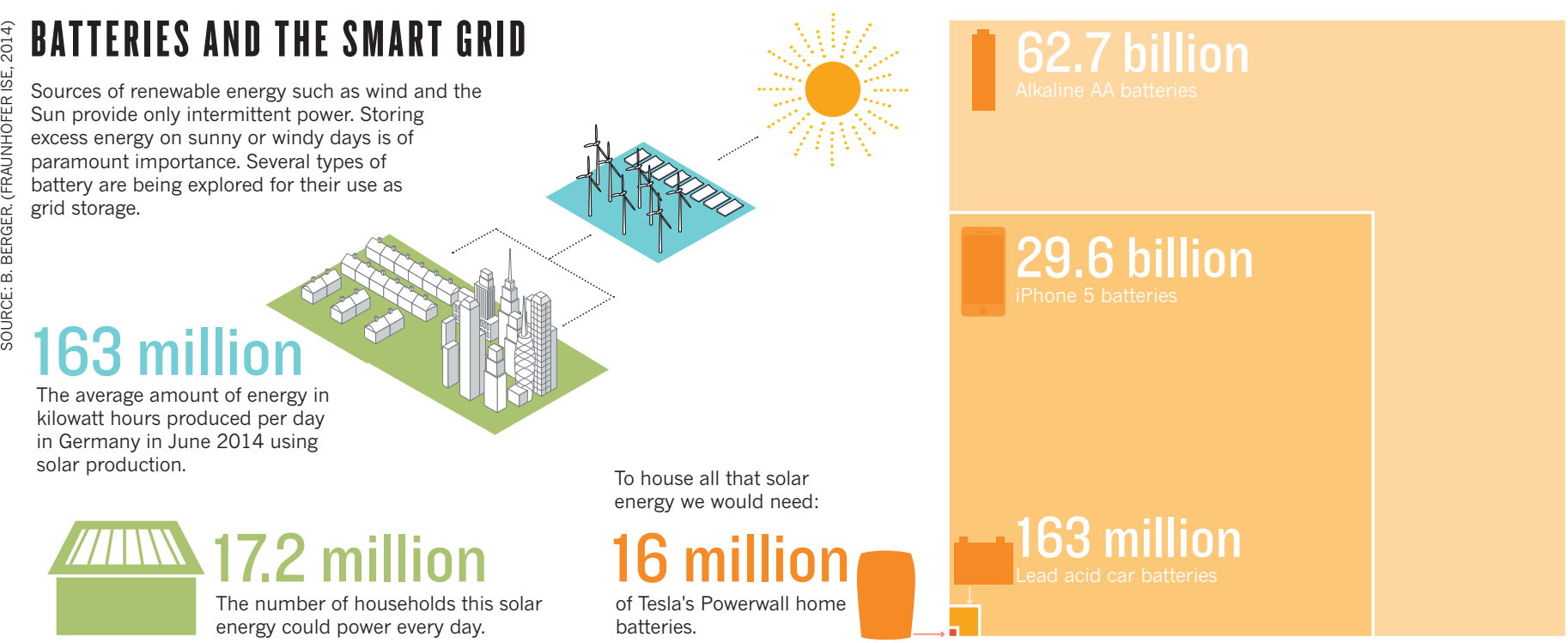

\section{RESOURCE SCARCITY}

Batteries contain materials that could eventually run out. Countries that are rich in these resources could one day hold the same sway as today's oil-rich countries. Lithium is one of the main concerns - demand for the metal has almost doubled in the past five years, with most of the world's supply coming from Latin America.

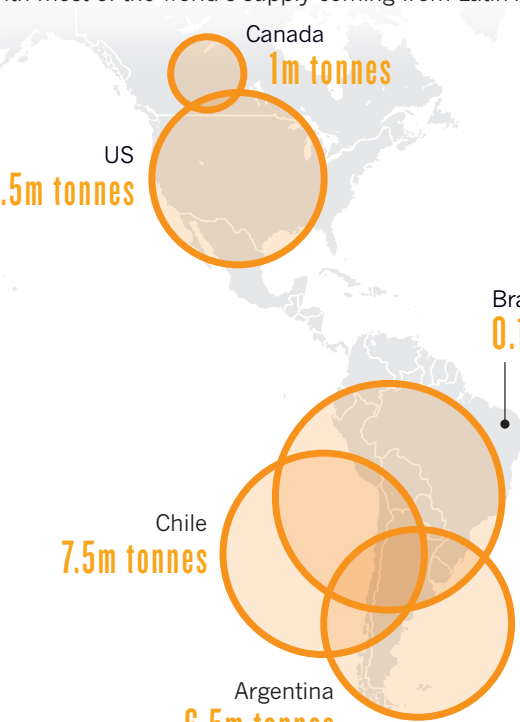

$6.5 m$ tonnes
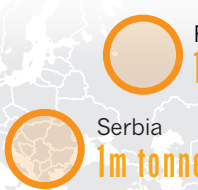

Russia $1 \mathrm{~m}$ tonnes

Bazil

$0.18 m$ tonnes

Bolivia

$9.0 m$ tonnes
$58 \%$

of lithium resources

come from Latin

America
The rechargeable-battery market of the future looks set to be dominated by lithium-ion batteries.

\section{Nickel metal hydride}

Best for high-current draw devices,

including mobile phones and laptops

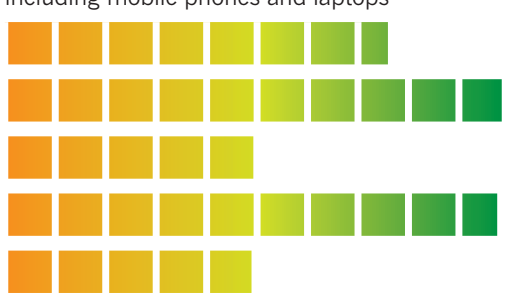

Poor

\section{Lithium ion}

Best for high-drain devices such as digital cameras, laptops and mobile phones

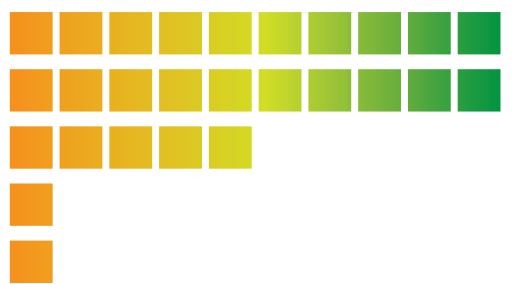

Poor

\section{Serbia}

Im tonnes

Democratic Republic of the Congo Im tonnes

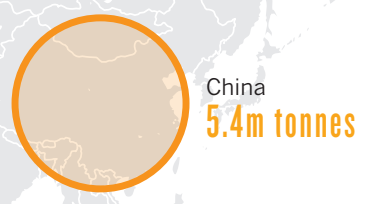

Lithium ion

Lead acid

Others

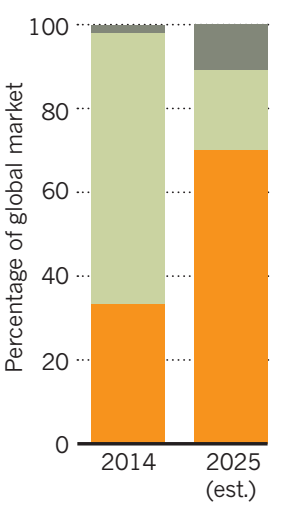

